\title{
O INCIDENTE DE RESOLUÇÃO DE DEMANDAS REPETITIVAS: ANÁLISE DA SUA UTILIZAÇÃO APÓS CINCO ANOS DE VIGÊNCIA DO CPC/2015
}

\author{
REPETITIVE DEMAND RESOLUTION INCIDENT: ANALYSIS \\ OF ITS USE AFTER FIVE YEARS OF CPC/2015
}

FREDERICO AUGUSTO LEOPOLDINO KOEHLER

Juiz federal do TRF5, atualmente juiz-instrutor no STJ. Mestre em direito público pela UFPE. Professor adjunto da UFPE e do PPGPD/Enfam. Membro e secretário adjunto do IBDP. Membro-fundador e secretário-geral da Annep.

https://orcid.org/0000-0002-0701-4443

SÍLVIO NEVES BAPTISTA FILHO Desembargador do Tribunal de Justiça de Pernambuco. Mestrando da Enfam. https://orcid.org/0000-0002-4254-129x

\section{RESUMO}

O Incidente de Resolução de Demandas Repetitivas - IRDR foi introduzido no Código de Processo Civil de 2015 com vistas a estimular o tratamento molecularizado de demandas que envolviam a mesma controvérsia de direito. Todavia, cinco anos após a entrada em vigor, o incidente ainda não atendeu à expectativa que se criou na fase anterior à vigência do referido código, de que o novo microssistema de precedentes pudesse modificar questões que sempre afligiram os processualistas, como o tratamento desigual às situações semelhantes, bem como a imprevisibilidade das decisões judiciais. O objetivo do estudo é analisar por que, mesmo diante da grande quantidade de demandas repetitivas surgindo a cada dia, e dos ganhos esperados, ainda não há um número significativo de IRDRs, e algumas possíveis causas da pouca adesão ao novo instituto. Utilizou-se como método de pesquisa a verificação dos números constantes dos bancos de dados do Conselho Nacional de Justiça - CNJ, dos tribunais de Justiça de São Paulo, do Rio de Janeiro e de Minas Gerais, além da pesquisa realizada pela Faculdade de Direito de Ribeirão Preto da Universidade de São Paulo - USP. Como conclusão, constatou-se que, após os cinco anos da vigência do Código de Processo Civil, os tribunais precisam estimular 
a propositura de demandas que gerem padrões decisórios; a limitação territorial não assegura a isonomia nem a segurança jurídica; e o não enfrentamento das matérias fáticas reduziu a abrangência da fixação dos precedentes.

Palavras-chave: processo civil; microssistema de precedentes no Código de Processo Civil; Incidente de Resolução de Demandas Repetitivas IRDR; princípio da eficiência no processo civil.

\section{ABSTRACT}

The Repetitive Demand Resolution Incident was introduced in the Civil Procedure Code to stimulate the molecular treatment of claims that involved the same legal controversy. However, 5 years after its entry into force, the incident has not yet met the initial expectation that the new precedent micro system could modify issues that have always afflicted the experts, such as different treatment of similar situations, as well as the unpredictability of judicial decisions. The object of this study is analyzing why, despite the large number of repetitive demands arising each day, there is still no significant number of RDRIs, and some possible causes of low adherence to the new institute. The research included the numbers contained in the databases of the CNJ, Courts of Appeals of São Paulo, Rio de Janeiro and Minas Gerais, and also the research carried out by the Faculty of Law of Ribeirão Preto of the University of São Paulo-USP. As a conclusion, it was found that after 5 years of the Civil Procedure Code, the courts need to stimulate demands that create precedents; territorial limitation does not guarantee isonomy, and the non-confrontation of fact matters reduced the scope of setting the precedents.

Keywords: civil procedure; repetitive demand resolution incident; precedents; principle of efficiency on civil procedure.

Recebido: $25-5-2021$

Aprovado: 28-6-2021

\section{SUMÁRIO}

1 Introdução. 2 Visão geral do problema. $3 \bigcirc$ procedimento adotado. 4 Política de estímulos à interposição do incidente. 5 A limitação da eficácia ao âmbito estadual ou regional. 6 Da opção legislativa pela impossibilidade de utilização do IRDR para dirimir matérias de fato 
repetitivas. 7 Suspensão dos processos e o risco do perecimento do direito. 8 Conclusão. Referências.

\section{INTRODUÇÃO}

O Incidente de Resolução de Demandas Repetitivas - IRDR foi concebido para integrar os microssistemas dos julgamentos repetitivos e de formação dos precedentes vinculantes. Com isso, pretendia-se estabelecer uma forma de racionalizar o julgamento das questões repetitivas, fixando precedentes de observância obrigatória e, consequentemente, oportunizando que os juízes de primeiro grau e tribunais pudessem julgar todos os processos sobre o assunto decidido no incidente de forma mais ágil e isonômica.

Ocorre que, em razão das questões que serão tratadas neste artigo, o incidente ainda não atendeu à expectativa que se criou na fase anterior à vigência do Código de Processo Civil de 2015, de que o novo microssistema de precedentes pudesse modificar questões que sempre afligiram os processualistas, como o tratamento desigual às situações semelhantes e a imprevisibilidade das decisões judiciais.

Da análise dos números constante do Painel de Consulta ao Banco Nacional de Demandas Repetitivas e Precedentes Obrigatórios do Conselho Nacional de Justiça - CNJ, é possível verificar que desde o início de 2016, ano em que entrou em vigor o novo Código de Processo Civil, foram admitidos no país 482 Incidentes de Resolução de Demandas Repetitivas, 180 recursos repetitivos e 148 reconhecimentos de repercussão geral. (CONSELHO NACIONAL DE JUSTICA, 2021)

Constata-se, ainda, que ao contrário do que se espera de um instituto recém-criado, o número de novos IRDRs não vem aumentando ano a ano, tendo sido 2020 o ano de menor distribuição desde 2016 , em que o atual código entrou em vigência. (CONSELHO NACIONAL DE JUSTIÇA, 2021)

Embora se verifique que o número de casos em todas as demais modalidades dos microssistemas de precedentes e de julgamento de demandas repetitivas não é superior aos de IRDR, o código espalhou a competência para a fixação de padrões decisórios para os tribunais de apelação, aumentando de dois para 83 o número de cortes com aquela 
competência', mas na prática faltam elementos para que haja uma mudança na cultura de julgamento de demandas repetitivas.

Este estudo objetiva analisar o porquê de, mesmo diante da grande quantidade de demandas repetitivas surgindo a cada dia e dos ganhos esperados para o Judiciário e jurisdicionados de um modo geral, ainda não haver um número significativo de IRDRs propostos, após cinco anos do início da vigência do novo Código de Processo Civil.

\section{VISÃO GERAL DO PROBLEMA}

A demanda desenfreada e massificada vem há anos abarrotando as unidades, gerando uma inevitável ineficiência do Poder Judiciário. O IRDR surgiu para contribuir com o resgate da eficiência, acelerando o tempo de resposta, diminuindo o custo da prestação do serviço, tornando previsível o comportamento dos julgadores e aumentando a segurança jurídica nas relações, uma vez que a imprevisibilidade e a demora na solução do conflito tornam desacreditada a Justiça e estimulam o não cumprimento das obrigações assumidas entre os contratantes ou participantes de demais relações interpessoais.

Embora o Relatório Justiça em Números 2020 do CNJ tenha demonstrado uma redução de 1,5 milhão de processos em relação ao ano anterior (2018), ao final de 2019 ainda existiam 77,1 milhões de casos aguardando solução definitiva. A produtividade média dos magistrados em 2019 cresceu 13\% em relação a 2018, mas o índice de conciliação permanece baixo, com uma pequena evolução em comparação com o período indicado. Estamos, portanto, longe de atender às expectativas da sociedade, acostumada a resolver suas necessidades básicas, ou até mesmo complexas, com poucos cliques em um smartphone. (CONSELHO NACIONAL DE JUSTICCA, 2020)

O mencionado relatório do CNJ afirma que o Brasil dispõe de 15.552 magistrados e quase cinco mil processos, em média, para cada julgador. Com esses números, não se atinge globalmente a eficiência

1 O Brasil dispõe de 83 tribunais e apelação com competência para propor o IRDR. São eles: 27 tribunais de Justiça, 27 tribunais regionais eleitorais, 5 tribunais regionais federais e 24 tribunais regionais do trabalho. 
prevista no art. $8^{\circ}$ do estatuto de processo civil ${ }^{2}$ nem se cumpre o desiderato de resolução das demandas em prazo razoável, consoante previsto no art. 5으, inciso LXXVIII, da Constituição da República. Os padrões decisórios, o Sistema Multiportas, a cooperação judiciária, dentre outras, são ferramentas que precisam se tornar realidade na cultura de quem trabalha no Judiciário e daqueles que a ele se dirigem para a resolução dos seus conflitos.

A limitação da capacidade de atender aos anseios da população exigiu do legislador, por ocasião das discussões do Código de Processo Civil, o desenvolvimento de uma ideia que, junto ao recurso especial e ao extraordinário repetitivos, fixasse padrões decisórios a partir dos tribunais de 2ำ grau. Optou-se por não incluir as matérias repetidas de fato como passíveis de serem apreciadas em sede de IRDR, e estabeleceram-se regras semelhantes aos demais institutos dos microssistemas de precedentes e de repetitivos.

○ incidente trata de situações homogêneas, mas não necessariamente idênticas, tendo por objetivo dirimir controvérsias sobre determinada questão de direito material ou processual. Não entraremos na discussão acalorada da doutrina se há fixação de tese ou julgamento de causa-piloto, cuja conclusão deverá ser seguida pelos demais órgãos julgadores vinculados. Para o propósito deste trabalho, importa saber que o IRDR é instaurado a partir de casos concretos, nos quais haja discussão sobre a questão de direito controvertida (TEMER, 2020, p. 76), a dimensão que o incidente atingiu, e quais entraves precisam ser ultrapassados para que se possa avançar no fim idealizado pelo código.

O IRDR foi inspirado no Musterverfahren do direito alemão e adquiriu feições próprias na redação do projeto do Código de 2015, na tentativa de adequá-lo às peculiaridades do sistema pátrio (KOEHLER, 2017, p. 248). O instituto alemão, curiosamente, vigorou até 2012, e surgiu para solucionar uma grande quantidade de demandas repetitivas

\footnotetext{
${ }^{2}$ CPC: Art. 8 Ao aplicar o ordenamento jurídico, o juiz atenderá aos fins sociais e às exigências do bem comum resguardando e promovendo a dignidade da pessoa humana e observando a proporcionalidade, a razoabilidade, a legalidade, a publicidade e a eficiência. CPC: Art. 4 As partes têm o direito de obter em prazo razoável a solução integral do mérito, incluída a atividade satisfativa. CF/88: Art. 5o Todos são iguais perante a lei, sem distinção de qualquer natureza, garantindo-se aos brasileiros e aos estrangeiros residentes no País a inviolabilidade do direito à vida, à liberdade, à igualdade, à segurança e à propriedade, nos termos seguintes: LXXVIII - a todos, no âmbito judicial e administrativo, são assegurados a razoável duração do processo e os meios que garantam a celeridade de sua tramitação.
} 
ligadas ao mercado de capitais. Uma das distinções desse modelo para o nosso diz respeito ao objeto do incidente. O Musterverfahren destina-se à resolução das questões fáticas e/ou jurídicas. O mérito da cognição no incidente alemão compreende elementos fáticos ou questões prévias (Vorfragen) de uma relação jurídica ou de fundamentos da pretensão individual. (CABRAL, 2007, p. 132)

Apesar de haver uma aproximação com a doutrina do stare decisis, a nossa solução não tem similitude com os sistemas de tradição anglosaxônica. Na Common Law, o precedente decorre de um caso concreto com questões de fato e de direito envolvidas. Não é a lei que determina a força vinculativa dos precedentes, mas a repetição de sua aplicação. Nos países que adotam esse sistema, o precedente não nasce obrigatório e só adquire essa condição com a repetição de sua observação.

A opção adotada pelo legislador pátrio foi de um modelo pré-fixado de vinculação dos precedentes. $\bigcirc$ art. 927 do código determina as hipóteses em que os tribunais deverão observar, incluindo os acórdãos em incidente de assunção de competência ou de resolução de demandas repetitivas, e em julgamento de recursos extraordinário e especial repetitivos.

O elo em comum nos casos do art. 927 é o procedimento previsto para julgamento e o contraditório qualificado. A ampliação do contraditório confere legitimidade constitucional e democrática à eficácia vinculante de que dotada a decisão a ser produzida por meio desse procedimento. (CÂMARA, 2018)

A ampliação é mecanismo essencial de conformação dos pronunciamentos que são produzidos ao modelo constitucional de processo, assegurando sua compatibilidade com o paradigma do Estado Democrático de Direito e, por conseguinte, legitimando a eficácia vinculante das decisões (CÂMARA, 2018). Ela garante, ainda, uma melhoria qualitativa da decisão que servirá como paradigma para o julgamento de casos idênticos. (CÂMARA, 2018)

Não obstante o empenho do legislador na tentativa de mudar a cultura dos atores das contendas judiciais e ampliar o sistema de precedentes vinculantes para combater a demanda desenfreada, o fato é que o número de Incidentes de Resolução de Demandas Repetitivas é pequeno se comparado à expectativa criada antes da entrada em vigor do código, bem como do imenso terreno inexplorado, principalmente. 
Não se tem a pretensão com esse estudo de esgotar as causas da pouca adesão pelos tribunais ao novo instituto, mas avaliar dentre os itens abaixo, quais deles podem ser considerados entraves ou barreiras para o aumento do número de IRDRs: I) o procedimento; II) o pouco empenho dos tribunais em estabelecer uma política de estímulo ao uso e à fixação de precedentes; III) a limitação da eficácia ao âmbito estadual ou regional, que auxiliaria a manutenção da cultura de se aguardar o posicionamento dos tribunais superiores; IV) a utilização em matéria unicamente de direito, excluindo as questões fáticas; e $\vee$ ) o risco de perecimento do direito devido à suspensão por um longo período das demandas afetadas.

\section{O PROCEDIMENTO ADOTADO}

O Incidente de Resolução de Demandas Repetitivas surgiu em cumprimento ao propósito de ampliar os microssistemas de resolução de demandas repetitivas e de precedentes judiciais para, com a ampliação da cognição e do contraditório, a qualificação do debate, a ampla publicidade e a fundamentação reforçada da decisão possibilitar não só a criação de um padrão decisório, mas também a possibilidade de aplicar o referido padrão a todos os processos cuja matéria tenha sido afetada e decidida.

A opção por criar um modelo de precedente estabelecido previamente demandou uma cautela justificável, mas que impede o IRDR de se tornar uma realidade rotineira. Se até a entrada em vigor do código apenas o STJ e o STF poderiam fixar os precedentes, essa função foi expandida para os tribunais estaduais, regionais federais e do trabalho, além dos militares e eleitorais.

Para a admissão do IRDR, é necessária a configuração de prévia controvérsia para demonstrar o risco à isonomia e à segurança jurídica. Inexistindo conflito de entendimentos, não há o risco de tratamento desigual. Essa exigência da controvérsia não se aplica aos processos originários dos tribunais. A simples repetição para órgãos julgadores diversos no mesmo tribunal configura o risco. (DIDIER; CUNHA, 2020, p. 775)

O código estabeleceu seis etapas até o julgamento: i) admissibilidade pelo colegiado competente para julgar o incidente; ii) suspensão dos processos pendentes, individuais ou coletivos, que tramitam no estado ou na região; iii) anotação no banco eletrônico de dados atualizados com informações específicas sobre questões de direito submetidas ao incidente; iv) ampla e específica divulgação e 
publicidade, por meio de registro eletrônico no Conselho Nacional de Justiça; v) instrução com a qualificação do contraditório, participação de amici curiae e manifestação do Ministério Público; e vi) julgamento.

Embora razoável, o fato de ser um órgão qualificado para admitir o processamento do incidente torna a instauração um pouco mais demorada devido ao número de votantes do órgão competente para a apreciação, geralmente superior às turmas e câmaras. É nesse momento que se verifica o preenchimento dos requisitos do art. 976, principalmente se a matéria é unicamente de direito, se há de fato questão repetitiva, e qual a controvérsia a ser dirimida. O que precisa ser repetido é a questão unicamente de direito, inexistindo necessidade de as demandas serem idênticas. (DIDIER; CUNHA, 2020, p. 775)

Admitido o incidente, compete ao relator decidir sobre a suspensão dos processos que tramitam no estado ou na região pelo período de um ano, que poderá ser prorrogado mediante decisão fundamentada 3 . A leitura do art. 982, inciso I, leva à conclusão de que não haveria outra alternativa senão suspender todos os processos uma vez admitido o IRDR. Todavia, a jurisprudência do STJ e do STF há muito admitem a não suspensão para os casos de recursos repetitivos, bem como para os casos de repercussão geral. Por se tratar de ponto importante na análise do problema trazido neste estudo, a questão será tratada com mais detalhe adiante.

Uma vez instaurado o IRDR, é incumbência do relator determinar a anotação no banco eletrônico específico de dados, que deverá ser atualizado com informações sobre questões de direito submetidas ao incidente. Essa medida é importante para que se dê publicidade ao IRDR, facilitando o acompanhamento por todos os interessados.

A ampla divulgação prevista no art. 979 diz respeito não só à comunicação ao Conselho Nacional de Justiça, mas também a todos os magistrados que possuem demandas cuja questão será decidida para que possam suspender os processos e comunicar as partes.

A instrução do incidente é a etapa que mais contribui para a demora e a consequente ineficiência do julgamento. Os arts. 982 e 983 determinam que o relator poderá requisitar informações a órgãos em

\footnotetext{
${ }^{3}$ Art. 980. O incidente será julgado no prazo de 1 (um) ano e terá preferência sobre os demais feitos, ressalvados os que envolvam réu preso e os pedidos de habeas corpus. Parágrafo único. Superado o prazo previsto no caput, cessa a suspensão dos processos prevista no art. 982, salvo decisão fundamentada do relator em sentido contrário.
} 
cujo juízo tramitem processos com o mesmo objeto da controvérsia para que respondam no prazo de 15 dias. Após as informações, o relator ouvirá pessoas, órgãos ou entidades com interesse na controvérsia, no prazo comum também de 15 dias. Em seguida, intimará o Ministério Público para, caso tenha interesse, manifestar-se em igual período.

Saliente-se que a ouvida de pessoas, órgãos e entidades com interesse na demanda, e a realização de audiência pública, não é uma faculdade do relator, mas condição indispensável para que a decisão a ser tomada possua força vinculante.

Por outro lado, o contraditório no IRDR não é o embate de teses antagônicas, mas o direito de defender o entendimento sobre a matéria que irá determinar a conclusão do seu caso concreto ${ }^{4}$.

Visando à garantia da segurança jurídica, as partes, a Defensoria Pública, o Ministério Público, ou qualquer parte de processo em curso no qual se discuta a mesma questão objeto do IRDR, independente da demanda correr em outro estado ou região, poderão requerer ao STJ ou STF, a depender da questão de direito a ser decidida, a suspensão de todos os processos individuais ou coletivos em curso no território nacional que versem sobre a questão objeto do incidente instaurado.

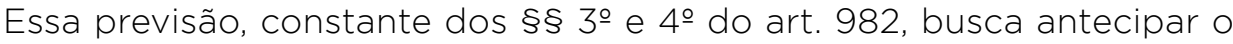
efeito do futuro recurso endereçado ao tribunal superior, considerando que a decisão proferida em sede de especial ou extraordinário dará efeito vinculante no território nacional ${ }^{5}$.

Por fim, por ocasião do julgamento, as partes, o Ministério Público e amici curiae poderão sustentar oralmente, antes que o relator e os demais integrantes do órgão julgador profiram seus votos. $\bigcirc$ acórdão, por força do $\$ 2^{\circ}$ do art. 984, abrangerá obrigatoriamente a análise de todos os fundamentos suscitados concernentes à tese jurídica discutida, sejam favoráveis ou contrários.

\footnotetext{
4 "O incidente se assemelha ao espaço público em que são apresentados fundamentos racionais para a tomada de decisões. O 'teste do debate público', ou seja, a tentativa de refutação através de argumentos racionais, é o que legitima a decisão proferida no IRDR perante toda a sociedade, e, por consequência, a posterior eficácia da decisão sobre a esfera dos sujeitos das demandas repetitivas. Não é a sua participação pessoal, mas sua participação 'virtual' no convencimento para a fixação da tese, através do teste de aceitabilidade racional." (TEMER, 2020, p. 157)

${ }^{5}$ Art. 987, § 2 .
} 
A tese fixada deve reproduzir a ratio decidendi, ou seja, o extrato da decisão que de fato vincula as unidades subordinadas ao tribunal e os seus órgãos fracionários.

Merece destaque o fato de que a decisão do IRDR só terá eficácia vinculativa, arts. 927, inciso III, e 985, caso tenham sido observados os procedimentos e as prerrogativas previstas para legitimar a decisão, notadamente as de participação no debate, e de fundamentação exaustiva, ou seja, a inclusão de todos os elementos trazidos, favoráveis e contrários à tese fixada. (TEMER, 2020, p. 235)

O art. 984, § 2expressamente determina que constem do acórdão todos os fundamentos relativos à questão jurídica apreciada, sejam eles contrários ou favoráveis. Essa exigência serve para demonstrar a superioridade racional da posição adotada, e também para possibilitar o enquadramento dos casos concretos, bem como os casos em que houver as distinções. (TEMER, 2020, p. 238)

Da decisão, caberá recurso especial ou extraordinário, que, nos termos do art. 987, § 1, terá necessariamente efeito suspensivo.

Em pesquisa realizada pelo Grupo Observatório Brasileiro de IRDRs, da Faculdade de Direito de Ribeirão Preto, da Universidade de São Paulo, publicada em novembro de 2019, com dados coletados entre os dias 18 de março de 2016 e 15 de junho de 2018 em todos os tribunais regionais federais e estaduais, constatou-se que o tempo médio entre a admissão e o julgamento do mérito é de 9,29 meses (UNIVERSIDADE DE SÃO PAULO, 2019). A pesquisa não considerou o tempo entre a distribuição e o julgamento do incidente.

Não obstante a quantidade de etapas, o contraditório qualificado, com audiências públicas, participação de amici curiae e demais interessados na controvérsia etc., não se pode dizer que o tempo médio de julgamento foi afetado por elas, ao ponto de se considerar um entrave à proliferação dos IRDRs.

Por outro lado, a burocracia exigida e o trabalho extra para o tribunal, associados à ausência de uma política voltada para a fixação de padrões decisórios, podem gerar uma resistência com as demandas repetitivas. 


\section{POLÍTICA DE ESTÍMULOS À INTERPOSIÇÃO DO INCIDENTE}

Não resta dúvida que a gestão e a fixação dos precedentes fazem parte da política judiciária e precisam do incentivo e da estrutura para que mais IRDRs sejam propostos.

Conforme conclusão do tópico anterior, o proponente precisa perceber um ambiente propício para a propositura do incidente, e compete aos gestores a elaboração dos estímulos para que cada vez mais incidentes sejam ingressados e julgados.

Chama atenção o fato de os três maiores tribunais de Justiça do país terem poucos IRDRs julgados ou em andamento. O TJSP possui 38 temas (SÃO PAULO, 2021); o TJRJ, 19 (RIO DE JANEIRO, 2021); e o TJMG tem 68. (MINAS GERAIS, 2021)

Por sua vez, no Banco Nacional de Dados de Demandas Repetitivas e Precedentes Obrigatórios - BNPR (CONSELHO NACIONAL DE JUSTIÇA, 2021), gerido pelo CNJ, há o registro de 186 IRDRs admitidos nos 89 tribunais com competência para processar e julgar, e 120 com trânsito em julgado.

Pela quantidade de demandas repetitivas nos três tribunais de grande porte citados, e ainda o número total de incidentes admitidos e/ ou com trânsito em julgado, percebe-se claramente que o número está aquém do potencial a ser explorado.

Esse caminho a ser percorrido depende única e exclusivamente da assimilação pelos tribunais, e pelos atores com possibilidade de propor o processamento: partes, Defensoria Pública, Ministério Público, juízes e relatores, da importância de se modificar a cultura e compreender que a eficiência do Judiciário passa pelo enfrentamento das demandas predatórias. Quanto maior a capacidade dos juízes de apreciar rapidamente a quantidade desumana de processos que chega todos os anos, maior será a sua capacidade de melhor prestar um serviço jurisdicional condizente com a expectativa da sociedade.

Uma unidade abarrotada de processos massificados impede a observância adequada das demandas únicas, ou seja, quanto mais processos repetitivos um juiz recebe, menos tempo ele tem para dedicar-se aos processos que exigem maior atenção e um trabalho mais artesanal. 
Assim, para a melhoria da eficiência do Judiciário, os tribunais precisam modificar a política dos precedentes e estimular ao máximo a propositura de demandas que gerem padrões decisórios, como o IRDR.

\section{A LIMITAÇÃO DA EFICÁCIA AO ÂMBITO ESTADUAL OU REGIONAL}

Ao ser julgado o incidente, a tese jurídica será aplicada a todos os processos individuais ou coletivos que versem sobre idêntica questão de direito e que tramitem na área de jurisdição do respectivo tribunal, inclusive nos juizados especiais do respectivo estado ou região6.

O IRDR surgiu para diminuir o problema da insegurança jurídica e ofensa à isonomia, transferindo a competência do julgamento da questão de direito controvertida para o colegiado designado pelos regimentos internos dos tribunais, visando à unificação do entendimento. Não obstante, o § 3이 do art. 982 possibilita a qualquer legitimado mencionado no art. 977, incisos II e III, requerer ao STJ ou STF, a depender da natureza da questão jurídica submetida, a suspensão de todos os processos individuais ou coletivos em curso no território nacional.

Essa possibilidade demonstra que o próprio código admite que a limitação territorial não assegura a isonomia nem a segurança jurídica, principalmente em uma era em que as barreiras geográficas estão cada vez menos presentes.

O número de empresas e pessoas que se relacionam comercial ou pessoalmente com residentes de outros estados aumenta exponencialmente a cada dia. Quando diferentes tribunais criam padrões decisórios distintos, estabelecendo uma regra geral e homogênea que se aplica a um único - ou a alguns - estados da federação, tal conduta afronta o núcleo da concepção do IRDR, aumentando a ausência da isonomia e a insegurança.

Outra situação intrigante ocorre quando a questão for relacionada à prestação de serviço público concedido, permitido ou autorizado. Nesses casos, o tribunal deve comunicar a tese adotada ao órgão, ao ente ou à agência reguladora competente para fiscalização da efetiva aplicação aos entes sujeitos à regulação․ Essa atitude pode fazer com

\footnotetext{
${ }^{6}$ Art. 985, I.

7 Art. 985, \& 2‥
} 
que o ente público seja obrigado a fiscalizar o mesmo serviço de forma distinta, a depender do estado ou da região.

De fato, as verdadeiras isonomia e segurança jurídicas só ocorrem com o julgamento de um eventual recurso aos tribunais superiores, ou em caso do pedido de suspensão previsto no art. 987. Todavia, até o presente momento, só houve oito pedidos de suspensão (SIRDRs) (BRASIL, 2021), demonstrando que a suspensão nacional ainda é uma possibilidade não utilizada.

Por essa razão, a limitação territorial do incidente, embora não interfira na propositura, prejudica o cumprimento do objetivo traçado pela lei e pelos princípios da isonomia e da segurança jurídica.

\section{DA OPÇÃO LEGISLATIVA PELA IMPOSSIBILIDADE DE UTILIZAÇÃO DO IRDR PARA DIRIMIR MATÉRIAS DE FATO REPETITIVAS}

O incidente de resolução de demandas repetitivas é admissível quando identificada, em primeiro grau, controvérsia com potencial de gerar multiplicação expressiva de demandas e o correlato risco da coexistência de decisões conflitantes.

A exposição de motivos do Código de Processo Civil de 2015 afirma que o Incidente de Resolução de Demandas Repetitivas teve inspiração no direito alemão, mais precisamente no Musterverfahren, experiência que criava modelos para a resolução de demandas em que as partes estivessem na mesma situação.

No modelo inspirador, todavia, não havia a exclusão das demandas que envolvessem questões de fato, até porque o instituto surgiu com a propositura de milhares de ações envolvendo uma fraude no mercado de capitais, onde a matéria fática preponderava.

A impossibilidade de o incidente ser proposto para julgamento de matérias de fato repetitivas pode ser justificada pela impossibilidade de os tribunais superiores reapreciarem as matérias de prova.

Se fosse possível a apreciação de matérias que não unicamente de direito, teríamos a situação esdrúxula das matérias de direito poderem ser revisadas pelos tribunais superiores, e as de fato se 
encerrarem nas cortes de apelação, não atingindo ao status de padrão decisório para o território nacional.

Antônio do Passo Cabral (2007, p. 132) afirma que no Musterverfahren não havia cisão estrita entre questões de fato e de direito. No objeto da cognição judicial, fato e direito estão indissociavelmente imbricados, e a dissociação radical poderia levar a um artificialismo da decisão.

Por sua vez, Fredie Didier ensina que toda questão de direito pressupõe a ocorrência de um fato, e distingue a questão de fato como aquela relacionada à causa de pedir ou à hipótese fática prevista no texto normativo, enquanto a questão de direito seria a relacionada às consequências jurídicas de determinada circunstância, ou à aplicação da hipótese de incidência prevista no texto normativo com as tarefas da subsunção do fato (ou conjunto de fatos) à norma, ou de concretização do texto legal. (DIDIER JR., 2015, p. 439)

Mesmo não adentrando na discussão do que seria a matéria exclusivamente de direito, e da eventual impossibilidade de separá-la da fática, ao fazer a opção, o código diminuiu a abrangência da fixação dos precedentes e prejudicou a intenção de se criar padrões decisórios que fossem capazes de diminuir o excesso de demandas que impedem a eficiência na resposta do Poder Judiciário.

Embora não se possa afirmar que a opção adotada é a razão para a timidez dos tribunais na proliferação dos IRDRs, não resta dúvida que se impôs um obstáculo significativo na criação de padrões decisórios e, sobretudo, na mudança da nossa cultura processual de imprevisibilidade e insegurança jurídica no tratamento de questões idênticas ou mesmo análogas.

\section{SUSPENSÃO DOS PROCESSOS E O RISCO DO PERECIMENTO DO DIREITO}

De acordo com o disposto no art. 982, inciso I, após ser admitido, o relator suspenderá os processos pendentes, individuais ou coletivos, que tramitam no estado ou na região, a depender se o tribunal for estadual ou regional.

O art. 1.037 traz uma regra semelhante ao afirmar que o relator, preenchidos os requisitos, proferirá decisão de afetação e, ao afetar, determinará a suspensão do processamento de todos os processos 
pendentes, individuais ou coletivos, que versem sobre a questão e tramitem no território nacional.

Todavia, a jurisprudência do STJ há muito vem relativizando a compulsoriedade da suspensão dos processos, evitando, em alguns casos, a paralisação prolongada em todo o país, e o risco do perecimento do direito pleiteado.

Na hipótese do Incidente de Resolução de Demandas Repetitivas, a situação é ainda mais drástica. Com a admissibilidade e a suspensão de todos os processos, eles permanecerão suspensos por até um ano, salvo decisão fundamentada em sentido contrário ${ }^{8}$, ou até o julgamento do recurso especial ou extraordinário, conforme a matéria9 .

Caso a suspensão não seja, por qualquer motivo, prorrogada após o período de um ano, os processos voltarão ao curso normal. Com a interposição do recurso, este terá efeito suspensivo ope legis ${ }^{10}$, e o acórdão só passará a surtir efeito após o pronunciamento do STJ ou do STF.

Por outro lado, se pensarmos em uma situação em que ocorra a suspensão, a prorrogação e a interposição de recurso para um dos tribunais superiores, o processo pode ficar paralisado na unidade por dois ou três anos, prejudicando as partes e o bom andamento da unidade judiciária, além do risco do perecimento do direito.

Embora a suspensão possa favorecer a isonomia e a segurança jurídica, com a possibilidade de se dar o mesmo tratamento a todos os casos com a mesma controvérsia, a demora exagerada causará danos ainda maiores ao jurisdicionado.

Como solução, Sofia Temer (2020, p. 146) traz em sua obra uma ideia interessante para evitar o prejuízo da paralisação de todos os processos pendentes, às vezes milhares deles, principalmente nos casos em que há um posicionamento da Corte praticamente pacificado. A ideia seria uma interpretação provisória, ou seja, uma tutela de urgência decidida por ocasião da decisão que aprecia o juízo de admissibilidade, em que se fixaria um entendimento provisório, por ela chamado de interpretação provisória. Esse entendimento poderia ser confirmado quando do julgamento do IRDR, ou caso houvesse modificação do entendimento, a modulação dos efeitos para os casos julgados anteriormente.

\footnotetext{
${ }^{8}$ Art. 980, parágrafo único.

${ }^{9}$ Art. 982, § 5․

${ }^{10} \mathrm{Art.} 987, \S 10$
} 
Ainda que a suspensão seja uma determinação legal, a melhor opção é avaliar o caso concreto e buscar a melhor medida a depender do tipo de demanda e do grau de pacificação do entendimento.

Portanto, não obstante o fato de a suspensão poder causar prejuízo às partes, não se pode afirmar que a medida afeta a propositura em si do IRDR, mas quando muito, o bom andamento do processo posteriormente ao juízo de admissibilidade.

\section{CONCLUSÃO}

Considerando os pontos tratados neste estudo, é possível concluir que:

i) Não obstante a quantidade de etapas, o contraditório qualificado, com audiências públicas, participação de amici curiae e demais interessados na controvérsia etc., não se pode dizer que o tempo médio de julgamento é afetado por elas, ao ponto de se considerar um entrave à proliferação dos IRDRs;

ii) A eficiência do Judiciário passa pelo enfrentamento das demandas predatórias. Quanto maior a capacidade dos juízos de apreciar rapidamente a quantidade desumana de processos que chega todos os anos, maior será a sua capacidade de melhor prestar um serviço jurisdicional condizente com a expectativa da sociedade;

iii) Para a melhoria da eficiência do Judiciário, os tribunais precisam modificar a política dos precedentes e estimular ao máximo a propositura de demandas que gerem padrões decisórios como o IRDR;

iv) A limitação territorial ao âmbito estadual ou regional não assegura a isonomia nem a segurança jurídica, principalmente em uma era em que as barreiras geográficas estão cada vez menos presentes. A verdadeira pacificação da matéria debatida, com o ganho decorrente em isonomia e segurança jurídica, ocorre apenas com o julgamento do recurso pelos tribunais superiores;

v) A limitação territorial do incidente, embora não interfira na propositura, prejudica o cumprimento do objetivo traçado pela lei e pelos princípios da isonomia e da segurança jurídica; 
vi) A sistemática adotada pelo código, de não enfrentar as matérias fáticas repetitivas, reduziu a abrangência da fixação dos precedentes e prejudicou a intenção, quando do início da sua vigência, de se criar padrões decisórios que fossem capazes de diminuir o excesso de demandas que impedem a resposta pelo Poder Judiciário em prazo razoável;

vii) Embora não se possa afirmar que a opção adotada seja a razão para a timidez dos tribunais na proliferação dos IRDRs, não resta dúvida que se impôs um obstáculo significativo na criação de padrões decisórios e, sobretudo, na mudança da nossa cultura processual de imprevisibilidade e insegurança jurídica no tratamento de questões idênticas ou análogas; e

viii) Ainda que a suspensão possa causar prejuízo às partes, não se pode afirmar que a medida afeta propositura em si do IRDR, mas quando muito, o bom andamento do processo posteriormente ao juízo de admissibilidade.

Da exposição dos pontos acima, e partindo da premissa que a quantidade de demandas repetitivas é superior à capacidade do Judiciário de fornecer respostas individualizadas, chegamos à conclusão de que, após cinco anos da vigência do Código de Processo Civil, os ganhos esperados com o IRDR ainda não foram experimentados em todo o seu potencial, porque não há uma quantidade significativa de incidentes propostos, e, menos ainda, admitidos. Por essas razões, os benefícios ainda são tímidos para a enorme carga de trabalho despendida no julgamento de demandas repetitivas. 


\section{REFERÊNCIAS}

BRASIL. [Constituição (1988)]. Constituição da República Federativa do Brasil. Brasília: Presidência da República, 1988. Disponível em: http:// planalto.gov.br/ccivil_03/constituicao/constituicao.htm. Acesso: em 5 fev. 2021.

BRASIL. Lei n. 13.105, de 16 de março de 2015. Código de Processo Civil. Brasília: Presidência da República, 2015. Disponível em: http:// www.planalto.gov.br/ccivil_03/_Ato2015-2018/2015/Lei/L13105.htm. Acesso em: 5 fev. 2021.

BRASIL. Superior Tribunal de Justiça. Núcleo de Gerenciamento de Precedentes - NUGEP. Brasília: STJ, 2021. Disponível em: https://processo.stj.jus.br/repetitivos/temas_repetitivos/pesquisa. jsp?novaConsulta=true\&pesquisarPlurais=on\&pesquisarSinonimos=on\&tipo pesquisa=T\&tipo_pesquisa=C\&tipo_pesquisa=|\&tipo_pesquisa=S\&pesquisa_ livre=. Acesso em: 3 fev. 2021.

CABRAL, Antônio do Passo. O novo procedimento-modelo (Musterverfahren) alemão: uma alternativa às ações coletivas. Revista de Processo, São Paulo, v. 32, n. 147, maio 2007.

CÂMARA, Alexandre de Freitas. Levando os padrões decisórios a sério. São Paulo: Atlas, 2018. Edição do Kindle.

CONSELHO NACIONAL DE JUSTICCA (Brasil). Justiça em números 2020. Brasília: CNJ, 2020.

CONSELHO NACIONAL DE JUSTICCA (Brasil). Painel de consulta ao Banco Nacional de Demandas Repetitivas e Precedentes Obrigatórios. Brasília: CNJ, 2021. Disponível em: https://paineis.cnj. jus.br/QvAJAXZfc/opendoc.htm?document=qvw_l\%2FPainelCNJ. qvw\&host $=$ QVS\%40neodimio03\&anonymous=true\&sheet=shDRGraficos. Acesso em: 4 fev. 2021.

DIDIER JR., Fredie; CUNHA, Leonardo Carneiro da. Curso de direito processual civil: meios de impugnação às decisões judiciais e processos nos tribunais. 17. ed. Salvador: JusPodivm, 2020. v. 3.

DIDIER JR., Fredie. Curso de direito processual civil: introdução ao direito processual civil: parte geral e processo de conhecimento. 17. ed. Salvador: JusPodivm, 2015. v. 1. 
KOEHLER, Frederico Augusto Leopoldino. Questões polêmicas da aplicação do Incidente de Resolução de Demandas Repetitivas (IRDR) no Microssistema dos Juizados Especiais. Direito Federal: Revista da AJUFE, São Paulo, v. 30, n. 96, jan./jun. 2017.

MINAS GERAIS. Tribunal de Justiça de Minas Gerais. Núcleo de Gerenciamento de Precedentes - NUGEP. Belo Horizonte: TJMG, 2021. Disponível em: http://rupe.tjmg.jus.br/rupe/justica/publico/bnpr/ consultarlrdrlacAdmitidos.rupe. Acesso em: 3 fev. 2021.

RIO DE JANEIRO. Tribunal de Justiça do Rio de Janeiro. Núcleo de Gerenciamento de Precedentes - NUGEP. Rio de Janeiro: TJRJ, 2021. Disponível em: http://www4.tjrj.jus.br/precedentes/ ConsultarPrecedentes.aspx. Acesso em: 3 fev. 2021.

SÃO PAULO (ESTADO). Tribunal de Justiça de São Paulo. Núcleo de Gerenciamento de Precedentes e Ações Coletivas. São Paulo: TJSP, 2021. Disponível em: https://www.tjsp.jus.br/NugepNac//rdr/ DetalheTema?codigoNoticia=62739\&pagina=1. Acesso em: 5 fev.2021.

TEMER, Sofia. Incidente de resolução de demandas repetitivas. 4. ed. Salvador: JusPodivm, 2020.

UNIVERSIDADE DE SÃO PAULO. Grupo de Estudos da Faculdade de Direito de Ribeirão Preto. Relatório de Pesquisa Observatório Brasileiro de IRDRs. São Paulo, nov. 2019. Disponível em: http:// observatorioirdr.direitorp.usp.br/o-incidente-de-resolucao-dedemandas-repetitivas/. Acesso em: 2 fev. 2021. 